\title{
A mediação como instrumento de resolução de conflitos baseada na teoria da ação comunicativa de Habermas*
}

\section{Mediation as democratic instrument of conflict resolution based on communicative action of Habermas}

\author{
Ana Carolina Ghisleni* \\ Fabiana Marion Spengler ${ }^{* * *}$
}

\section{Resumo}

A mediação é um mecanismo de tratamento de conflitos capaz de restabelecer a comunicação rompida entre os litigantes; ao mesmo tempo, é promotora da democracia e se baseia na ação comunicativa de Habermas. Para melhor entendê-la, é importante discutir a própria democracia, tão necessária para a construção de uma cidadania ativa, baseada na ampla participação social e no

O presente texto foi produzido mediante pesquisa junto ao projeto: "Acesso à justiça, jurisdição (in)eficaz e mediação: a delimitação e a busca de outras estratégias na resolução de conflitos", financiado pelos recursos do Edital FAPERGS n 02/2011 - Programa Pesquisador Gaúcho (PqG), edição 2011, e pelos recursos do Edital CNPq/CAPES nº 07/2011, processo nº 400969/2011-4.

* Mestre em Direito pelo Programa de Pós-Graduação em Direito da Universidade de Santa Cruz do Sul-UNISC, integrante do Grupo de Pesquisas "Políticas Públicas no tratamento dos conflitos", do projeto de pesquisa "Mediação de conflitos para uma justiça rápida e eficaz" financiado pelo CNPQ (Edital Universal 2009 - processo 470795/2009-3) e pela FAPERGS (Edital RecémDoutor 03/2009, processo 0901814), mediadora judicial junto ao projeto de extensão "A crise da jurisdição e a cultura da paz: a mediação como meio democrático, autônomo e consensuado de tratar conflitos". Santa Cruz do Sul - Rio Grande do Sul - Brasil. Email: anacghisleni@hotmail. com

*** Doutora em Direito pelo programa de Pós-Graduação stricto sensu da Universidade do Vale do Rio dos Sinos - UNISINOS - RS, mestre em Desenvolvimento Regional, com concentração na área Político Institucional da Universidade de Santa Cruz do Sul - UNISC - RS, docente dos cursos de Graduação e Pós Graduação lato e stricto sensu da última instituição, Coordenadora do Grupo de Estudos "Políticas Públicas no Tratamento dos Conflitos" vinculado ao CNPQ, coordenadora do projeto de pesquisa "Mediação de conflitos para uma justiça rápida e eficaz" financiado pelo CNPQ (Edital Universal 2009 - processo 470795/2009-3) e pela FAPERGS (Edital Recém-Doutor 03/2009, processo 0901814), coordenadora e mediadora judicial junto ao projeto de extensão "A crise da jurisdição e a cultura da paz: a mediação como meio democrático, autônomo e consensuado de tratar conflitos", advogada. Santa Cruz do Sul - Rio Grande do Sul - Brasil. Email: fabiana@unisc.br 
entendimento do sujeito como ator constitutivo do poder político. A democracia não passa de um conceito abrangente e complexo que compreende a política do indivíduo. Da mesma forma, estuda-se a teoria da ação comunicativa proposta por Habermas, que se interliga ao tema por meio da interlocução política do sujeito. Em sua teoria, o agir comunicativo pressupõe a utilização da racionalidade recíproca, isto é, a utilização do agir orientado para o entendimento, que ocorre com a utilização da mediação de conflitos. Nesse contexto, a mediação possibilita a interlocução política de todos os atores que são afetados pela gestão pública, como também a abertura de um campo de ampla comunicação entre sociedade civil organizada e as tradicionais instituições existentes, contribuindo para a expansão dos debates de interesse social. Assim, tal instrumento de resolução de conflitos estimula a participação individual e a autonomia privada, auxiliando na construção da necessária mudança de cultura, que consiste na participação do processo democrático e no exercício da cidadania.

Palavras-chave: Ação comunicativa. Conflito. Democracia. Mediação. Política.

\section{Abstract}

Mediation is a mechanism of conflict resolution able to restore the disrupted communication between litigants; at the same time, promotes democracy based in the theory of communicative action from Habermas. To better a understanding of the subject, it is important to discuss democracy, necessary to construction of active citizenship based in broad social participation and understanding of individuals as agents of political power. Democracy is an embracing and complex concept that means the politics of individual. Hence, the theory of communicative action from Habermas is studied, since it interconnects directly in this dialogue through the political dialogue of subjects. In such theory, communicative action presupposes utilization of reciprocal rationality, in other words, use of act guide to understanding what occurs with the use of conflict mediation. In this context, mediation enables the political dialogue of the actors affected by the public management as well as opening a wide area of communication between civil society and traditional institutions, expanding social discussions. So, this instrument of conflict resolution stimulates individual and private autonomy, helping building of necessary change of culture that means social participation in democratic process and exercise of citizenship.

Keywords: Communicative action. Conflict. Democracy. Mediation. Policy. 


\section{Introdução}

A mediação é um instrumento democrático de tratamento de controvérsias e se embasa fundamentalmente na teoria da ação comunicativa de Habermas. O presente estudo propõe, portanto, a discussão básica de temas como mediação, democracia e teoria proposta por Habermas, para, ao final, analisar de que forma a primeira contribui para a construção de uma sociedade democrática. Nesse sentido, as dificuldades de concretização de uma democracia deliberativa amparada na ampla participação social crescem à medida que o direito vem sendo descumprido e é respeitado tão somente em face de seu caráter coercitivo, bem como em razão da ausência de cultura política pela sociedade civil, que permanece impassível frente aos interesses públicos (TOURAINE, 1996, p. 44)1. Convencionouse afirmar que a atividade de administrar tais interesses nasce com o Estado, mais precisamente com o Estado de Direito.

No entanto, em face da pluralidade da sociedade contemporânea e da evolução da própria política, necessita-se de outro modelo que não seja centrado fundamentalmente no Estado, mas capaz de revisar seus paradigmas filosóficos e epistemológicos. Trata-se de uma concepção baseada numa racionalidade comunicativa, permitindo um envolvimento do Estado com o cidadão na busca de um entendimento.

Ao analisar o impasse das democracias contemporâneas, Jürgen Habermas propõe uma teoria do Direito Político, fundamentando-o em uma nova percepção: na integração normativa das interações estratégicas livres da moral tradicional (GOYARD-FABRE, 2003), o que implica em permanentes e tensionais pactos de civilidade. Habermas busca, assim, resgatar a legitimidade do próprio direito por meio do Estado Democrático de Direito, de forma que o cidadão participe da elaboração da norma que ele mesmo vai cumprir.

Muitas vezes, o governo é percebido como algo à parte do mundo das pessoas comuns: elas não vivem, diz-se, no mundo que é nosso (TOURAINE, 1996). 
Nesse caso, como a atividade comunicacional é constitutiva da sociedade, assim também as bases do direito só podem ser encontradas no pensamento da intersubjetividade. Desse modo, uma norma jurídica deve buscar sua validade no consenso, que é resultado da discussão prática entre os diversos membros de uma comunidade. Tal entendimento busca a concretização da cidadania e a participação social ativa, uma vez que o sujeito é considerado competente e apto para, mediante debate argumentativo, questionar o sistema de normas e buscar novos princípios normativos, na tentativa de reorganizar a sociedade.

Portanto, o estudo proposto busca analisar, por meio da obra de Jürgen Habermas, as teorias da democracia e estabelecer a conceituação de uma sociedade democrática, para, posteriormente, caracterizar a cidadania e a participação social, considerando os sujeitos como atores constitutivos do poder político e de seu exercício. Pretende, ainda, apresentar pressupostos de uma administração comunicativa fundamentada na construção de pactos semânticos e pragmáticos de comunicação, fragmentando a ideia da democracia representativa e reforçando a necessidade de uma democracia mais do que participativa para, por fim, analisar a mediação - mecanismo de abertura e desconcentração do poder - como um instrumento democrático no tratamento de conflitos e constitutivo desse novo modelo.

\section{As teorias da democracia, sociedade democrática, cidadania ativa e participação social: aspectos conceituais}

A democracia é entendida não somente como um conjunto de garantias institucionais (liberdade negativa), mas como a luta dos sujeitos envolvidos por sua cultura e liberdade contra a lógica dominadora dos sistemas; conforme a expressão lançada por Robert Fraisse, ela é a "política do sujeito" (TOURAINE, 1996, p. 24).

O sujeito, portanto, é condição política de existência da democracia; seu eixo central é a ideia de soberania popular, ou seja, a afirmação de que a ordem política é produzida pela ação humana. O poder do 
povo significa a capacidade reconhecida ao maior número possível de pessoas para viverem livremente, construindo sua vida individual através da associação entre o que são e o que pretendem ser, e da resistência ao poder em nome tanto da liberdade quanto da fidelidade a uma herança cultural (TOURAINE, 1996, p. 25).

Nesse caso, a democracia "não reduz o ser humano a ser apenas um cidadão; reconhece-o como um indivíduo livre que também faz parte de coletividades econômicas ou culturais". Logo, a igualdade política é outra condição de existência da democracia, porém, aquela não se define somente pela atribuição dos mesmos direitos a todos os cidadãos; "é também um meio de compensar as desigualdades sociais, em nome dos direitos morais" (TOURAINE, 1996, p. 29).

Para Touraine (1996), a definição de democracia está atrelada a três dimensões necessárias: livre escolha, em intervalos regulares, dos governantes pelos governados ${ }^{2}$. Não há poder popular considerado democrático se não tiver sido outorgado e renovado pela livre escolha, da mesma forma que não há democracia sem o direito de voto por parte dos governados.

Essa visão tridimensional abrange três componentes: em um primeiro momento, a representatividade dos governantes, ou seja, "a existência de atores sociais cujos agentes políticos sejam os instrumentos, os representantes"3. A segunda característica compreende

2 A democracia existe realmente quando a distância que separa o Estado da vida privada é reconhecida e garantida por instituições políticas e pela lei. Ela não se reduz a procedimentos porque representa um conjunto de mediações entre a unidade do Estado e a multiplicidade dos atores sociais. É preciso que sejam garantidos os direitos fundamentais dos indivíduos; é preciso, também, que estes se sintam cidadãos e participem da construção da vida coletiva. Portanto, é preciso que os dois mundos - o Estado e a sociedade civil -, que devem permanecer separados, fiquem também ligados um ao outro pela representatividade dos dirigentes políticos. Essas três dimensões da democracia - respeito pelos direitos fundamentais, cidadania e representatividade dos dirigentes - se completam; aliás, é sua interdependência que constitui a democracia (TOURAINE, 1996, p. 43).

3 Observa-se que a pluralidade dos atores políticos é inseparável da autonomia e do papel determinantes das relações sociais; uma sociedade política que não reconhece essa pluralidade das relações e dos atores sociais não apresenta condições de ser considerada democrática ainda que o governo ou partido no poder insistam sobre a maioria que os apoia e, portanto, sobre seu sentido do interesse geral (TOURAINE, 1996). 
o fato de que os eleitores são e se consideram cidadãos, interessandose pelo governo e sentindo-se parte de uma sociedade política ${ }^{4}$. Por fim, o terceiro atributo consiste na limitação do poder dos governantes em face da existência da própria eleição, bem como em respeito às leis que definem os limites no interior dos quais o poder se exerce ${ }^{5}$ (TOURAINE, 1996, pp. 44-46).

Embora se perceba a existência de aspectos importantes entre as três dimensões da democracia, não existe, entre elas, um equilíbrio ou um tipo de democracia ideal. Ao contrário, elas geram, de acordo com a posição predominante ocupada por uma ou outra, três tipos principais de democracias. "O primeiro tipo dá uma importância central à limitação do poder do Estado pela lei e pelo reconhecimento dos direitos fundamentais", de modo que essa concepção liberal se adapta facilmente à limitação da representatividade dos governantes, ao mesmo tempo em que protege os direitos sociais.

O segundo tipo valoriza mais a cidadania, a Constituição ou as ideias morais que garantem a integração da sociedade, fornecendo um palpável fundamento para as leis. Nesse modelo, a igualdade prevalece sobre a liberdade. Já o terceiro tipo dá maior importância à representatividade social dos governantes, opondo a democracia à oligarquia.

A democracia também se relaciona diretamente com o culturalismo, que leva o respeito pelas minorias até a supressão da própria ideia de maioria e a uma redução extrema do domínio da lei ${ }^{6}$.

4 Para Touraine (1996, p. 44), essa consciência de filiação ao governo e esse sentimento de cidadania nem sempre existem; muitas vezes, o governo é percebido como algo à parte do mundo das pessoas comuns. Porém, ainda que a ideia de cidadania não se reduza à ideia democrática, não é possível conceber uma democracia que não se apoie na definição de cidadania.

5 É indispensável, para a democracia, a recusa de toda essencialidade do poder; tal postura é manifestada concretamente pela lei da maioria (TOURAINE, 1996).

6 A democracia não se define pela separação dos poderes, mas pela natureza dos elos entre sociedade civil, sociedade política e Estado. Se a influência for exercida de cima para baixo, não existirá democracia; pelo contrário, é considerada democrática a sociedade em que os atores sociais orientam seus representantes políticos, os quais, por sua vez, controlam o Estado (TOURAINE, 1996, p. 51). 
Por isso, o Estado Democrático deve reconhecer aos cidadãos menos favorecidos o direito de agir, dentro da lei, contra uma ordem desigual da qual o próprio Estado faz parte. Nesse sentido, Ronald Dworkin - um dos melhores representantes da escola liberal - refere que a igualdade política pressupõe que todos os membros de uma mesma comunidade sejam tratados pelo governo com respeito e atenção equivalentes (tanto os mais fracos quanto os mais poderosos ou favorecidos) (TOURAINE, 1996, p. 27).

Dworkin entende que o direito não se limita a um conjunto de normas, mas possui uma dimensão moral integradora, revelada na existência de princípios. "o argumento jurídico é um argumento típica e completamente moral” (DWORKIN, 2010, p. 205). Uma teoria política completa do direito inclui pelo menos duas partes principais, que devem apoiar-se mutuamente: tanto os fundamentos do direito como a força do direito, ou seja, respectivamente, "circunstâncias nas quais proposições jurídicas específicas devem ser aceitas como bem fundadas ou verdadeiras", bem como "o relativo poder que tem toda e qualquer verdadeira proposição jurídica de justificar a coerção em vários tipos de circunstâncias excepcionais" (DWORKIN, 1999, p. 136).

Logo, o direito, na concepção de Dworkin, ultrapassa a dimensão instrumental e passa a ser, em uma concepção hermenêutica, uma atitude interpretativa, cuja legitimidade se encontra na reciprocidade ${ }^{7}$. Mais do que isso, "uma verdadeira comunidade política deve tratar os seus integrantes como cidadãos que possuem igual status político e moral". Essa igualdade exige a atribuição de direitos fundamentais aos cidadãos, para que eles tenham a oportunidade de participar, influenciar a vida política e assumir responsabilidades pelas decisões que sua autonomia Ihes assegura (CITTADINO, 2000, pp. 153-156).

Os indivíduos que integram as democracias contemporâneas compartilham uma concepção de justiça segundo a qual todos os cidadãos devem ser tratados com igual respeito (CITTADINO, 2000). 
Já para Kelsen (2000, p. 27), a síntese da liberdade e igualdade é a característica principal da democracia. Entretanto, o autor discute amplamente a questão da liberdade como a reação existente contra a coerção resultante do estado de sociedade e o protesto contra a vontade alheia. Nesse sentido, "o peso da vontade alheia, imposto pela vida em sociedade, parece tanto mais opressivo quanto mais diretamente se exprime no homem o sentimento primitivo do próprio valor".

Em face da existência da sociedade e, mais ainda, do Estado, "deve haver um regulamento obrigatório das relações dos homens entre si, deve haver um poder". Desse modo, a chamada liberdade natural se transforma em liberdade social ou política; contudo, "é politicamente livre aquele que está submetido, sim, mas à vontade própria e não alheia". Difícil, portanto, encontrar uma forma de associação que defenda e proteja um membro a ela pertencente de forma que tal indivíduo se una aos demais, obedeça a si mesmo e permaneça livre como antes (KELSEN, 2000, p. 28).

Por isso, "a existência da sociedade ou do Estado pressupõe que possa haver discordância entre a ordem social e a vontade daqueles que se lhe submetem". A democracia, portanto, em favor dessa ordem social, renuncia à unanimidade e se contenta com as decisões tomadas pela maioria, de forma que a autonomia individual considera o sujeito submisso à própria vontade, mas vale a lei da maioria, demonstrando "novo progresso da metamorfose da ideia de liberdade" (KELSEN, 2000, p. 30).

Uma sociedade democrática, desse modo, combina a liberdade dos indivíduos e o respeito pelas diferenças com a organização racional da vida coletiva pelas técnicas e leis das administrações pública e privada. O individualismo não é um princípio suficiente para a construção da democracia. $O$ indivíduo guiado por seus interesses, pela satisfação de suas necessidades, ou até mesmo pela recusa de modelos centrais de conduta, nem sempre é portador de uma cultura democrática, embora seja mais fácil que ele prospere em uma sociedade democrática do que em qualquer outra, porque a democracia não se reduz a um mercado político aberto (TOURAINE, 1996, p. 28). 
De outro lado, inúmeros sinais demonstram que os regimes chamados democráticos podem enfraquecer e estão submetidos às exigências do mercado mundial, protegido e regulado pelos principais centros do poder econômico. Isso acarreta uma crise da representação política, que, por sua vez, provoca a diminuição da participação política. Os eleitores deixam de se sentir representados e exprimem tal sentimento ao denunciarem uma classe política cujo único objetivo seria o próprio poder e, por vezes, o enriquecimento pessoal de seus membros (TOURAINE, 1996, p. 18).

A democracia, assim enfraquecida, pode ser destruída a partir de cima - por um poder autoritário - , a partir de baixo - pelo caos, violência e guerra civil - ,ou a partir de si mesma - pelo controle exercido sobre o poder pelas oligarquias ou partidos que acumulam recursos econômicos ou políticos para impor suas escolhas a cidadãos reduzidos ao papel de eleitores (TOURAINE, 1996).

Essa falta de cultura democrática também se relaciona diretamente com a ausência da consciência de filiação a uma comunidade política, e tudo isso se reflete na cidadania. Isso significa dizer que a relação entre democracia e cidadania é forte: "a democracia se apoia na responsabilidade dos cidadãos de um país". Contudo, não existe cidadania sem esse sentimento de filiação a uma identidade política, pois, se os cidadãos não se sentem responsáveis, "não pode haver representatividade dos dirigentes ou livre escolha destes pelos dirigidos".

"A ideia de cidadania proclama a responsabilidade política de cada um e, portanto, defende a organização voluntária da vida social contra as lógicas não políticas" - chamadas por alguns de "naturais" - do mercado ou do interesse nacional ${ }^{8}$. Por isso, a força principal da democracia reside na vontade dos cidadãos em agirem de maneira responsável na vida pública: "o espírito democrático forma uma consciência coletiva,

A cidadania não pode ser confundida com a nacionalidade, embora suas noções sejam próximas. A segunda designa a filiação a um Estado nacional, enquanto a primeira fundamenta o direito de participar, direta ou indiretamente, na gestão da sociedade (TOURAINE, 1996). 
enquanto os regimes autoritários se apoiam na identificação de cada pessoa com um líder, símbolo ou ser social coletivo, em particular, com a nação" (TOURAINE, 1996, pp. 97-98).

Contudo, não basta falar de combinação de democracia com cidadania como se fosse "uma síntese de unidade e diversidade, de racionalidade instrumental e respeito pela identidade cultural individual e coletiva" sem discorrer acerca dos atores sociais. É necessário ponderar sobre o sujeito como integrante de identidades e técnicas, construindose como ator capaz de modificar seu meio ambiente e transformar sua realidade (TOURAINE, 1996, p. 171).

A ideia de sujeito combina três elementos cujas presenças são igualmente indispensáveis: trata-se da resistência à dominação; do amor de si, pelo qual o indivíduo estabelece sua liberdade como condição principal de sua felicidade e o reconhecimento dos outros como sujeitos; bem como o consequente apoio às regras políticas e jurídicas que proporcionam ao maior número possível de pessoas o máximo de oportunidades de viver como sujeitos ${ }^{9}$ (TOURAINE, 1996, p. 172).

A democracia deve auxiliar os indivíduos a se tornarem sujeitos e conseguirem "a integração não só de sua racionalidade, isto é, sua capacidade para manipular técnicas e linguagens, mas também de sua identidade que se apoia em uma cultura e tradição", reinterpretadas constantemente $^{10}$ (TOURAINE, 1996, pp. 175-177).

$\mathrm{Na}$ verdade, "democracia significa identidade entre governantes e governados, entre sujeito e objeto do poder, governo do povo sobre o povo", e esse povo é uma pluralidade de indivíduos que formam uma unidade. Consequentemente, "o indivíduo isolado não tem, politicamente,

9 Conforme Touraine (1996), o sujeito é simultaneamente razão, liberdade e memória. Essas três dimensões correspondem às da democracia, porque o apelo a uma identidade coletiva deve ser traduzido na organização política pela representação dos interesses e valores dos diferentes grupos sociais.

10 O sujeito deve ser visto como uma rede de comunicação entre os universos da objetividade e subjetividade, que não devem estar separados um do outro nem artificialmente fundidos (TOURAINE, 1996). 
nenhuma existência real, não podendo exercer influência real sobre a formação da vontade do Estado"; por isso, a democracia só existirá se os indivíduos se agruparem conforme suas afinidades políticas, a fim de dirigir a vontade geral para seu fim político (KELSEN, 2000, pp. 37-40).

Desse modo, a cultura democrática só pode existir se a sociedade política for concebida como uma construção institucional, cujo objetivo principal é combinar a liberdade dos indivíduos e coletividades com a unidade da atividade econômica e das regras jurídicas.

Após essas considerações iniciais, é necessário distinguir, ainda, democracia representativa, participativa e deliberativa. A primeira consiste na escolha dos representantes feita pelo povo, por meio do voto. Os partidos políticos são importantes organizações para influenciar ou ocupar o poder e, nesse modelo, a opinião popular só é consultada uma vez a cada quatro anos. Durante esse intervalo de tempo, os eleitos podem agir da forma que entenderem ser adequada. Embora tenha sido responsável por evoluções históricas e importantes conquistas estatais, tal modelo é considerado ultrapassado e decadente, sendo alvo de muitas críticas, na medida em que o povo não participa ativamente e, dessa forma, as chances de manipulação e condução pelos dominantes, em face de sua autonomia, são amplas.

$\mathrm{Na}$ democracia participativa, por sua vez, o povo, além de escolher seus representantes, participa de forma impetuosa da administração mediante consultas populares existentes ao longo da governança, vinculando os chefes de governo às decisões e necessidades da sociedade. Os mecanismos existentes que possibilitam essa interlocução são o plebiscito, o referendo e a iniciativa popular ${ }^{11}$. A democracia deliberativa, por fim, vai além da participativa: há uma extensa participação política, através de debates, de organizações civis e da sociedade no processo de democratização. Possui ênfase

11 Tais instrumentos não serão estudados de forma aprofundada em face da complexidade do tema e limitação do espaço. 
nos aspectos discursivos do processo político e a visão normativa é associada à participação de todos nas discussões como critério de legitimidade.

Mais do que isso, na democracia deliberativa, os líderes devem dar razões que justifiquem as suas decisões e responder às razões que, por sua vez, são apresentadas pelos cidadãos. Isso serve tanto para produzir uma decisão justificada como para expressar o valor do respeito mútuo. Não é suficiente que os cidadãos afirmem o seu poder através de negociações baseadas no interesse de grupos particulares ou através de eleições. Seu maior teórico é Jürgen Habermas, o qual acredita na reconstrução democrática da esfera pública por meio de uma perspectiva emancipatória que contemple a implementação de procedimentos racionais, discursivos, participativos e pluralistas, conforme será apresentado no próximo capítulo.

\section{A interlocução política e os sujeitos como atores constitutivos do poder político por meio da ação comunicativa de Jürgen Habermas}

Os procedimentos racionais permitem aos sujeitos, no enfrentamento das conflitualidades sociais emergentes, desenvolver mecanismos de coordenação da ação social com base nos princípio sético-normativos da racionalidade comunicativa. $O$ crescimento exponencial da credibilidade referente à democracia deliberativa se deu, dentre outros motivos, em face da possibilidade que ela traz de produzir resultados políticos justos e adequados. Também em razão da crise de representatividade política ${ }^{12}$, traduzida no declínio do comparecimento eleitoral; na ampliação da desconfiança dos cidadãos em relação às

12 A crise da representação política é responsável pelo enfraquecimento da participação popular na vida política em geral. Quando os atores políticos não estão submetidos às demandas dos atores sociais, perdem sua representatividade e se tornam desequilibrados; assim, podem pender para o lado do Estado e destruir a primeira condição de existência da democracia: a limitação do poder (TOURAINE, 1996, p. 79). 
instituições políticas; no esvaziamento dos partidos políticos, por causa da burocratização de suas estruturas internas e crescente interferência da mídia junto ao processo eleitoral (LÜCHMANN, 2007).

Para Habermas, a integração das democracias contemporâneas tem duplo fundamento: a força resultante de um acordo racionalmente motivado e a ameaça das sanções. Isso significa que a ordem jurídica se baseia na facticidade e validade: dimensão coercitiva de um direito legalmente instituído e legitimidade resultante de um entendimento conjuntamente negociado, conectando diretamente o direito com a democracia, os direitos humanos com a soberania popular. O direito coercitivo só conserva sua força integradora porque os destinatários individuais das normas jurídicas podem reconhecer a si próprios como autores e destinatários de tais normas (CITTADINO, 2000, pp. 171-173).

Ademais, a sociedade civil compreende um sujeito por excelência da constituição da esfera pública como espaço coletivo de comunicação pública, dotado da capacidade de ampliação ou incorporação de novos temas, problemas e questões. Trata-se, nessa vertente teórica, de um conjunto de atores e instituições que se diferenciam dos partidos e de outras instituições políticas, bem como dos agentes e instituições econômicas. Pluralismo, autonomia, solidariedade, influências e impactos na esfera pública completam o quadro de características dessa concepção de sociedade civil moderna (HABERMAS, 1997).

O modelo proposto se fundamenta na ação comunicativa e procura compatibilizar o núcleo normativo da teoria da democracia com as complexas e diferenciadas estruturas da modernidade. Habermas estabelece um protótipo pelo qual a opinião pública gera influência, que se transforma em "poder comunicativo" através de eleições. Este, por sua vez, torna-se "poder administrativo" por meio da legislação (HABERMAS, 1997).

No pensamento habermasiano, o conceito de esfera pública ocupa uma posição central na elaboração teórica de democracia deliberativa e abarca a multiplicidade de espaços de argumentação pública envolvendo o embate dos diversos atores da sociedade. "O 
novo paradigma de direito só pode pertencer à razão comunicacional em funcionamento, no âmago do Estado de Direito Democrático, na discussão pública" (GOYARD-FABRE, 2003, p. 321).

Nesse contexto, o referido autor "pretende propor uma terapia por meio da nova conceituação que confere à 'razão comunicacional': ela rompe a clausura sistêmica de um direito curvado sobre as singularidades individuais", almejando moldar, no espaço público, uma ética de discussão. É a linguagem - "mídia universal" - que cria a possibilidade de comunicação; é desse modo que as relações interpessoais passam a ter prioridade sobre a individualidade (GOYARD-FABRE, 2003, p. 322).

Logo, "o paradigma do sujeito é assim evencido pelo paradigma da intersubjetividade que também é, de maneira concreta e pragmática, interação e intercompreensão". A partir dessas considerações, a discussão abre caminho para uma política deliberativa, posto que o sistema jurídico não responde mais às necessidades e reivindicações de uma opinião que o jurislador não escuta. O espaço público funciona como um sistema de alertas, dotado de antenas, formando uma espécie de estrutura de comunicação "mediadora entre os setores privados do mundo vivido e o sistema jurídico-político" (GOYARD-FABRE, 2003, p. 323).

O novo paradigma do direito, baseado na democracia processual e na política deliberativa, exige que a discussão argumentada predomine sobre a decisão voluntária do poder. A razão processual convoca a prática do entendimento consensual por meio do diálogo. Assim, "a validade das normas jurídicas depende de seu acordo com o mundo cotidiano vivido, que é o próprio télos do 'agir comunicacional'" (HABERMAS, 1997).

O agir comunicativo pressupõe a utilização da racionalidade recíproca, isto é, a utilização do agir orientado para o entendimento. O contato que os indivíduos possuem com o mundo é mediado linguisticamente, ao passo que a objetividade do mundo - que se supõe ao falar e agir - "está [...] entrelaçada com a intersubjetividade do entendimento sobre algo no mundo" (HABERMAS, 2002, p. 56). 
A racionalidade comunicativa "exprime-se na força unificadora da fala orientada ao entendimento mútuo, discurso que assegura aos falantes envolvidos um mundo da vida intersubjetivamente partilhado", como também o horizonte pelo qual todos podem "se referir a um único e mesmo mundo objetivo" (HABERMAS, 2004, p. 107).

A partir da fundamentação da política deliberativa indicada por Habermas, demarca-se a possibilidade de conceber uma esfera pública autônoma que, formada argumentativamente em um processo racional de consenso, livre de coação, no interior da sociedade, outorga legitimidade aos processos de construção permanente da democracia ${ }^{13}$ (HABERMAS, 1997).

A ação comunicativa, portanto, é entendida como um tipo de ação social mediada pela comunicação, em cuja dimensão se encontra a possibilidade de reconhecer uma noção ampliada de racionalidade, capaz de resgatar e incorporar o interesse crítico e emancipatório das teorias. Em outras palavras, a compreensão da linguagem ocorre como uma forma de comunicação orientada para o entendimento subjetivo (HABERMAS, 1997).

$\mathrm{Na}$ verdade, a teoria da ação comunicativa é capaz de gerar uma efetiva democratização da sociedade e o exercício de cidadania mediante uma concepção discursiva da soberania popular, pois os pactos comunicativos viabilizam uma participação mais ativa por parte da sociedade civil. Ademais, propõe-se a ampliação e o desenvolvimento de espaços públicos comunicativos orientados para a formação democrática da opinião e da vontade comuns, através da realização de processos de entendimento intersubjetivo mediados pela linguagem, permitindo que se produzam deliberações em diversas áreas da comunicação (HABERMAS, 1997).

13 Constitui-se em uma dupla dimensão: de um lado, desenvolve processos de formação democrática de opinião pública e da vontade política coletiva; de outro, vincula-se a um projeto de construção de uma hegemonia democrática radical, em que a sociedade civil - esfera pública institucionalizada - se torna uma instância de deliberação e de legitimidade da práxis democrática (HABERMAS, 1997). 
Para formular o modelo democrático procedimental, Habermas analisa a legitimação do direito, discorrendo sobre a relação existente entre a facticidade e a validade, ou seja, a tensão entre a autocompreensão normativa do Estado e a facticidade social dos processos políticos. 0 surgimento da política deliberativa, para o autor, "não depende de uma cidadania capaz de agir coletivamente, e sim da institucionalização dos correspondentes processos e pressupostos comunicacionais", associado também "ao jogo entre deliberações institucionalizadas e opiniões públicas que se formaram de modo informal" (HABERMAS, 1997).

O pluralismo social e cultural transforma a vida em um mundo desencantado, "onde os indivíduos relacionam-se entre si enquanto estranhos", de modo que somente o direito pode fornecer uma estrutura normativa capaz de regular essa interação. Com a teoria discursiva do direito, Habermas almeja afirmar que, diversamente das leis morais, "o direito positivo e seu potencial coercitivo precisam obter legitimidade através de um procedimento legislativo democrático" (CITTADINO, 2000, pp. 171-172).

Isso significa referir que há uma relação muito próxima entre direito e democracia, "que se traduz na conexão intrínseca entre direitos humanos e soberania popular". Ou seja, como a ordem jurídica das sociedades contemporâneas assegura iguais liberdades subjetivas a todos os cidadãos mediante procedimento legislativo democrático do qual todos participam -, tais liberdades se conectam "com direitos de cidadania oriundos da plena autonomia política dos indivíduos" (CITTADINO, 2000, p. 173).

Nesse sentido, como a sociedade democrática é uma comunidade de cidadãos livres e iguais, o ordenamento jurídico "não pode ser um mero distribuidor de liberdades de ação de tipo privado"; no entanto, a distribuição dos direitos subjetivos só será igualitária na medida em que os cidadãos, na condição de legisladores, estabelecerem um consenso sobre os critérios de tratamento igual aos iguais e desigual aos desiguais (CITTADINO, 2000, p. 174). 
Assim, as autonomias pública e privada dos cidadãos têm a mesma origem e sua ligação "não pode ser estabelecida caso os cidadãos não reconheçam a existência de um sistema de direitos quando pretendem legitimamente regular as suas relações através do direito positivo". Uma vez estabelecida, portanto, uma intrínseca relação entre direito e democracia, não há como supor que o sistema de direitos deixará de considerar seriamente as diferenças culturais existentes entre comunidades específicas (CITTADINO, 2000, pp. 174-175).

É nesse ponto que a teoria discursiva do direito revela sua importância, pois permite a comunicação entre a autonomia pública e a privada, aproximando-as e reconstruindo um sistema de direitos que está na origem da associação voluntária de cidadãos que, legitimamente, elaboram o próprio direito positivo (CITTADINO, 2000, p. 179).

De fato, "com a teoria discursiva do Estado Democrático de Direito, Habermas pretende reconstruir a relação interna entre direito e poder político", de forma que tal modelo de Estado entenda o poder político não apenas revestido de forma jurídica, mas vinculando-o a um direito legitimamente promulgado (CITTADINO, 2000, p. 179).

Com a utilização, portanto, da teoria da ação comunicativa habermasiana, há uma interlocução política entre os sujeitos, os quais se tornam atores constitutivos do poder político. É tão somente nesse espaço público democrático, baseado na ampla comunicação entre sujeitos, que vão se constituir as legítimas políticas públicas aptas a implementarem a participação fundacional do cidadão, o qual tornarse-á corresponsável pelo próprio desenvolvimento e o da realidade em que vive.

Nesse contexto, a mediação de conflitos, principalmente em face de seu procedimento fundamentado na razão comunicativa, auxilia na busca pela solidificação do Estado Democrático de Direito. A utilização de instrumentos como a mediação evidencia a possibilidade da interlocução política de todos os atores que são afetados pela gestão pública, como também a abertura de um campo de ampla comunicação entre sociedade civil organizada e as tradicionais instituições existentes, 
contribuindo para a expansão dos debates de interesse social, conforme apresentado a seguir.

\section{A mediação de conflitos como prática democrática e constitutiva de uma democracia deliberativa}

A mediação de conflitos é uma forma de "instaurar a comunicação rompida entre as partes em virtude da posição antagônica instituída pelo litígio"; seu principal desafio é encontrar mecanismos que possibilitem uma convivência comunicativamente pacífica. Por isso, utiliza-se da teoria habermasiana para, através da busca pela racionalidade, gerar consenso e atuar como verdadeira estratégia política, abarcando o papel das subjetividades para renovação da sociedade (SPENGLER, 2010, p. 349).

Importante, nesse sentido, entender em que local essas práticas ocorrem dentro da ordem democrática, a partir da perspectiva proposta. Para tanto, infere-se que a mediação e as demais práticas de tratamento de litígios são formas de relacionar a sociedade e o Estado no âmbito do Poder Judiciário. Isso demonstra uma ampliação da participação social, na medida em que o sujeito percebe a possibilidade de participar por meio de outras instituições, além dos meios notórios já existentes, como o voto, parlamento, plebiscito, etc. ${ }^{14}$

A mediação, portanto, além de consistir em uma forma de concretizar a democracia deliberativa, torna-se prática consensuada de reestruturação comunicativa e facilitadora do diálogo público no âmbito da jurisdição. Ela permite que os conflitantes se comuniquem de forma ampla, na tentativa de resolver adequadamente o litígio existente, sem a imposição de uma decisão por terceira pessoa, como ocorre no processo judicial.

\footnotetext{
14 Outros exemplos de mecanismos que ampliam a participação individual cidadã consistem nos Conselhos Populares, no âmbito do Poder Executivo, e nas Comissões Temáticas, no Poder Legislativo.
} 
Sua interação ocorre pela ação comunicativa, a qual "se dá a partir da prática do consenso" e da racionalidade ${ }^{15}$. "A atenção volta-se à racionalidade imanente da prática comunicativa que remete às diversas formas de argumentação" e à capacidade de seguir na comunicação almejando o consenso (SPENGLER, 2010).

O tratamento de conflitos mediante a utilização da mediação pode acontecer em face de uma pluralidade de técnicas, e os contextos nos quais é possível aplicá-las são vários: judicial, familiar, ambiente de trabalho, entre outros. Todos possuem como base "o princípio de religar aquilo que se rompeu, restabelecendo uma relação para, na continuidade, tratar o conflito que deu origem ao rompimento", através da comunicação (SPENGLER, 2010, p. 319).

Dessa forma, a razão comunicativa "se expressa na fala orientada ao entendimento, possuindo como ponto central não o sujeito, mas o meio linguístico pelo qual se concatenam as interações", resultando na comunicação. Quanto maior é a racionalidade comunicativa, maior também a possibilidade de coordenar ações sem o emprego da coerção e resolver o litígio com a aplicação do consenso em conflitos acontecidos em decorrência de dissonâncias $\operatorname{cognitivas}^{16}$ (SPENGLER, 2010, p. 358).

A resolução de litígios por meio da mediação ocorre com a elaboração de um acordo pelas partes, contudo, sempre há o risco do desacordo, que é inerente do próprio mecanismo comunicativo: "os desacordos fazem parte do meio comunicativo, surgindo das experiências que perturbam os aspectos rotineiros e tidos como adquiridos, constituindo uma fonte de contingências". Pode acarretar, ainda, a frustração de expectativas e, nesse aspecto, o risco de

\footnotetext{
15 Na teoria habermasiana, a racionalidade possui relações profundas com a forma pela qual os sujeitos capazes de linguagem e de ação fazem uso do conhecimento linguístico (SPENGLER, 2010).

16 Conforme Spengler (2010), a racionalidade dos participantes é mensurada pela capacidade de fundamentar suas manifestações ou emissões nas situações certas.
} 
desacordo é absorvido, regulado e controlado nas práticas cotidianas (SPENGLER, 2010, p. 363).

É claro que o acordo "não pressupõe a concordância coletiva, embora esta seja a meta final, uma vez que a formação do consenso ${ }^{17}$ nasce de uma 'tensão explosiva entre facticidade e validez'". Isso significa que o consenso é a comunicação voltada ao entendimento, "compartilhando expectativas, buscando o acordo" (SPENGLER, 2010, p. 364).

Ocorrendo o dissenso, "os interlocutores buscam o restabelecimento do consenso por meio de argumentos, em decorrência da racionalidade comunicativa". Com efeito, o ato de argumentar nessa procura pela concordância é critério de racionalidade e recomendação prática para uma boa convivência (SPENGLER, 2010, p. 365).

Além disso, todo ato de fala (entendimento do falante com outra pessoa) "situa a expressão linguística em relação ao falante, ao ouvinte e ao mundo", e consiste no entendimento, coordenação da ação e socialização. Aquilo que entra na ação comunicativa mediante recursos do pano de fundo do mundo da vida possibilita o domínio das situações e constitui verdadeira reserva de conhecimento. Essa reserva se solidifica enquanto percorre o longo caminho da interpretação, transmitindo-se por paradigmas interpretativos.

Possuindo uma cadência temporal própria, colocando-se entre as partes e agindo como instrumento de justiça social, "a mediação pode organizar as relações sociais, auxiliando os conflitantes a tratarem os seus problemas com autonomia, reduzindo a dependência de um terceiro (juiz)", ao mesmo tempo em que acarreta entendimento mútuo e consenso (SPENGLER, 2010, p. 314).

\footnotetext{
17 Ibidem, p. 366. O consenso possui três ideias essenciais - escolha, confiança e razão. Tais conceitos constituem, juntos, o sinal de união entre os homens, de um comprometimento nascido de razões comuns e de uma prática inerente à democracia moderna. É nesses termos que o consenso nasce como uma estratégia mais democrática de gerir os desacordos/conflitos, permitindo que uma ação/relação comum se concretize.
} 
De outro lado, em face da complexidade da estrutura social, a utilização da coerção, caracterizada pela possibilidade de sanção, já não serve mais como elemento condutor do agir social em relações conflituosas. "Por isso, o consenso depende do reconhecimento intersubjetivo de pretensões de validez suscetíveis de crítica", e é a partir dele que se dá a ação comunicativa, modificando a equivocada ideia da necessidade de coerção.

Assim, inobstante a importância do Direito para a manutenção da paz na sociedade, "o consenso e a inclusão social surgem como alternativas no tratamento de controvérsias". O consenso, na verdade, torna-se um elo na formação da vontade coletiva ao mesmo tempo em que organiza a comunidade. Por isso a importância da mediação como mecanismo de sua concretização.

Portanto, quando a ação linguística se orienta para o entendimento, "o consenso dele surgido se fundamenta na validez de normas e de instituições, o que Ihe confere legitimidade, obtida em ambiente não repressivo e de participação efetiva" (SPENGLER, 2010, p. 365).

Mais que isso, a ação comunicativa, ao permitir esse discurso social na busca pelo consenso, dá importância justamente ao diálogo, à discussão em si. Como já referido, nem sempre o consenso é alcançado, por isso, o importante é sua busca, que ocorre por meio da discussão. O que vale é a discussão elaborada para chegar num entendimento; a comunicação entre os indivíduos.

Até porque, em uma sociedade complexa, como a que se vive atualmente, "o interesse público não pode ser somente confiado às instituições, mas reclama a iniciativa (e não somente a participação) dos cidadãos". Nesse ponto, a mediação é instrumento promotor de autonomia individual, na medida em que as partes são responsáveis pela decisão tomada ${ }^{18}$ (GARDINI, 2008, p. 125).

\footnotetext{
18 GARDINI, Gianluca. Os instrumentos de participação à ação pública. In: LEAL, Rogério Gesta (Org). A administração pública compartida no Brasil e na Itália: reflexões preliminares. Santa Cruz do Sul: Edunisc, 2008, p. 125.
} 
Vive-se um momento em que é necessária uma nova concepção de democracia, conforme Habermas refere em seu modelo de política deliberativa, estimulando a participação social e o interesse do cidadão pela política, gerando a consciência de filiação. Para auxiliar na densificação da democracia, necessário não somente oportunidades materiais de acesso da população à gestão pública da comunidade, mas, também, formas de sensibilização e mobilização dos indivíduos e de outras organizações à participação, por meio de rotinas e procedimentos didáticos que levem em conta as diferenças e especificidades de cada um.

É nessa conjuntura que as políticas públicas se tornam importantes mecanismos geradores de participação, contribuindo para o aumento da relação entre sociedade civil e Estado. Logo, a mediação, como instrumento comunicativo, permite que os conflitantes participem, inicialmente, da construção da decisão tomada, comprometendo-se, responsabilizando-se e instigando, posteriormente, uma participação mais ampla.

Isso significa dizer que a mediação de conflitos é uma forma de estimular a participação individual e a autonomia privada, auxiliando na construção da necessária mudança de cultura, para que os sujeitos não devam sempre esperar uma resposta estatal ${ }^{19}$, mas participar ativamente do processo democrático, exercendo a cidadania.

Para tanto, o Estado deve, certamente, não só "garantir a igualdade de oportunidades aos diferentes projetos de institucionalidade democrática, mas deve também garantir padrões mínimos de inclusão"20,

19 GARDINI, Gianluca. Os instrumentos de participação à ação pública. In: LEAL, Rogério Gesta (Org). A administração pública compartida no Brasil e na Itália: reflexões preliminares. Santa Cruz do Sul: Edunisc, 2008, p. 125.

20 Nesse sentido, como a mediação ocorre no âmbito do Poder Judiciário (no processo judicial), as partes normalmente esperam que a decisão seja tomada pelo juiz. A mudança de cultura proposta se inicia com a desvinculação da decisão pelo juiz no momento em que as partes percebem que elas mesmas podem decidir seus conflitos e que, dessa forma, haverá uma decisão muito mais democrática e satisfatória. 
possibilitando que a cidadania ativa auxilie na criação, acompanhamento e avaliação de políticas públicas e projetos de governo (LEAL, 2008, p. 201).

Portanto, utilizando de forma mais ampla a mediação de conflitos, os cidadãos poderão perceber que, além de decidir os próprios conflitos, podem e devem participar das decisões políticas de interesse público, auxiliando na construção de uma esfera pública baseada no amplo diálogo do Estado com a sociedade civil.

\section{Conclusão}

O novo paradigma democrático reconhece a necessidade da própria sociedade cumprir seus direitos e deveres através do exercício pleno da cidadania. A democracia deliberativa baseada na ação comunicativa trabalha com essa ideia e dispõe de instrumentos teóricos para sua efetivação, fazendo com que o cidadão se sinta parte do ente Estado-sociedade e participe da esfera pública.

No entendimento habermasiano, esse espaço público não passa de uma ligação entre os indivíduos e o âmbito estatal: ocorre uma ampliação de sua atividade com os interesses da sociedade. O modelo discursivo, nesse sentindo, torna-se adequado porquanto permite 0 ingresso de novos grupos na esfera pública ao mesmo tempo em que promove a expansão dos direitos e da cidadania.

Por meio da teoria discursiva de Habermas, o cidadão participa da elaboração da norma que vai cumprir, sentindo-se parte desse procedimento. A comunicação, o diálogo e a discussão almejando um entendimento são importantes e fundamentais para a concretização da teoria discursiva.

Esse novo modelo experimental de Estado e sociedade civil compreende o distanciamento do primeiro de algumas funções tradicionais que vinha exercendo e a aquisição de outras novas, mediante ações institucionais inovadoras e democráticas, compartilhando 
responsabilidades. A relação entre ambos se torna muito próxima em face, principalmente, da participação política e da cidadania, cujos mecanismos e instrumentos viabilizadores são criados pelo ente estatal.

Nesse contexto, a mediação, sendo instrumento restaurador da comunicação entre conflitantes, surge como importante ferramenta promotora da participação individual. Isso ocorre em face de seu procedimento baseado na autonomia individual, o qual permite a construção de uma decisão pelas partes, responsabilizando e comprometendo os conflitantes em relação ao cumprimento desta.

Além disso, a mediação dissolve os marcos de referência da certeza, determinados pelo conjunto normativo, postos e expostos de forma hierarquizada. É democrática porque acolhe a desordem - e, por conseguinte, o conflito - como possibilidade positiva de evolução social. É também democrática quanto ao fundamento da relação de um com o outro: é uma aposta na substituição do tratamento dos conflitos de maneira tradicional (Estado produtor de regulação e de jurisdição, único meio de resposta) por uma estratégia partilhada e convencionada, que tenha por base um Direito inclusivo.

\section{Referências}

CITTADINO, Gisele. Pluralismo, direito e justiça distributiva: elementos da filosofia constitucional contemporânea. 2. ed. Rio de Janeiro: Lumen Juris, 2000.

DWORKIN, Ronald. O império do direito. Tradução de Jefferson Luiz Camargo. São Paulo: Martins Fontes, 1999.

. A justiça de toga. Tradução de Jefferson Luiz Camargo. São Paulo: Martins Fontes, 2010.

GARDINI, Gianluca. Os instrumentos de participação à ação pública. In: LEAL, Rogério Gesta (Org.). A administração pública compartida no Brasil e na Itália: reflexões preliminares. Santa Cruz do Sul: Edunisc, 2008. p.104-130. 
GOYARD-FABRE, Simone. O que é democracia? Agenealogia filosófica de uma grande aventura humana. Tradução de Claudia Berliner. São Paulo: Martins Fontes, 2003.

HABERMAS, Jürgen. Agir comunicativo e razão destranscendentalizada. Tradução de Lúcia Aragão. Rio de Janeiro: Tempo Brasileiro, 2002.

. Direito e democracia: entre facticidade e validade. Rio de Janeiro: Tempo Brasileiro, 1997. 2 v.

. Verdade e justificação: ensaios filosóficos. Tradução de Milton Camargo Mota. São Paulo: Loyola, 2004.

KELSEN, Hans. Essência e valor da democracia. In: KELSEN, Hans. A democracia. São Paulo: Martins Fontes, 2000.

LEAL, Rogério Gesta. Esfera pública e participação social: possíveis dimensões jurídico-políticas dos direitos civis e de participação social no âmbito da gestão dos interesses públicos no Brasil. In: LEAL, Rogério Gesta (Org.). A administração pública compartida no Brasil e na Itália: reflexões preliminares. Santa Cruz do Sul: Edunisc, 2008. p. 177227.

LÜCHMANN, Lígia Helena Hahn. Democracia deliberativa, pobreza e participação política. Política \& Sociedade, Florianópolis, v. 6, n. 11, p.183-197, out. 2007.

SANTOS, Boaventura de Sousa (Org.). Democratizar a democracia: os caminhos da democracia participativa. 2. ed. Rio de Janeiro: Civilização Brasileira, 2003.

SOUZA, Jessé (Org.). Democracia hoje: novos desafios para a teoria democrática contemporânea. Brasília, DF: UnB, 2001.

SPENGLER, Fabiana Marion. Da jurisdição à mediação: por uma outra cultura no tratamento dos conflitos. Ijuí: Unijuí, 2010.

TOURAINE, Alain. O que é a democracia? Tradução de Guilherme João de Freitas Teixeira. Petrópolis: Vozes, 1996.

Recebido em: 27/02/12

Aprovado em: 19/10/12 